\title{
Development of microsatellite markers from four Hawaiian corals: Acropora cytherea, Fungia scutaria, Montipora capitata and Porites lobata
}

\author{
Gregory T. Concepcion • Nicholas R. Polato • \\ Iliana B. Baums $\cdot$ Robert J. Toonen
}

Received: 29 September 2009/Accepted: 4 October 2009/Published online: 5 November 2009

(c) The Author(s) 2009. This article is published with open access at Springerlink.com

\begin{abstract}
Comprehensive population genetic studies of coral communities are comparatively rare, because of the scarcity of population genetic markers. The Hawaiian archipelago offers a unique perspective into understanding the population genetic structuring of this ecologically important group of organisms. Here we report the development of microsatellite marker libraries from holobiont extracts of four corals: Acropora cytherea $(n=50)$, Fungia scutaria $(n=118)$, Montipora capitata $(n=140)$ and Porites lobata $(n=149)$. Blast searches indicate that these libraries contain microsatellites from both the coral host and Symbiodinium endosymbionts from each coral. In addition, we also present redesigned primers for the nuclear coding region $(\operatorname{atps} \beta)$ for use in $M$. capitata. We report testing and optimization for seven of these microsatellites from A. cytherea, and eight microsatellites and the atps $\beta$ locus from M. capitata. Using 25 individuals per species collected from each French Frigate Shoals (FF) and Johnston Atoll (JO), the number of alleles per locus ranged from 2 to 9. Expected heterozygosities ranged from 0.38 to 0.85 and 0.08 to 0.87 for A. cytherea and M. capitata,
\end{abstract}

Electronic supplementary material The online version of this article (doi:10.1007/s12686-009-9118-4) contains supplementary material, which is available to authorized users.

G. T. Concepcion $(\varangle) \cdot$ I. B. Baums · R. J. Toonen

Hawai'i Institute of Marine Biology, P.O. Box 1346,

Kaneohe, HI 96744, USA

e-mail: gconcepcion@gmail.com; gconcepc@ hotmail.com

I. B. Baums

e-mail: baums@psu.edu

N. R. Polato · I. B. Baums

Department of Biology, The Pennsylvania State University, 208 Mueller Laboratory, University Park, PA 16802, USA e-mail: Nrp146@psu.edu respectively. We expect that these libraries will be a valuable resource and provide additional useful microsatellite markers for both the coral host and zooxanthellae.

Keywords Scleractinian - Zooxanthellae · Symbiodinium - Connectivity · Population genetics · Phylogeography

Spanning 2,600 km, and ranging in age from a few hundred thousand to more than 60 million years, the isolated volcanic archipelago of Hawai' $i$ offers a unique opportunity to understand population connectivity in the marine environment. For sessile benthic marine organisms, the larval phase of the life history is the only part of the life cycle that allows for gene flow between populations, but it is difficult to track miniscule larvae across oceanic scales (Levin 2006). In order to gain insight into the historical patterns of coral colonization of the archipelago, microsatellite markers are incredibly useful tool for understanding population genetic structuring and inferring patterns of connectivity (Selkoe and Toonen 2006).

Total genomic DNA of Acropora cytherea, Fungia scutaria, Montipora capitata and Porites lobata were extracted in parallel according to the chloroform extraction protocol described in Concepcion et al. (2006). DNA from $A$. cytherea and $P$. lobata were digested with restriction enzyme BstU I, while DNA from $F$. scutaria and M. capitata were digested with restriction enzyme Rsa I. Using a slightly modified protocol from Glenn and Schable (2005), double stranded linkers were ligated to the $5^{\prime}$ end of restriction fragments. Enrichment probes consisted of two mixtures of $3^{\prime}$ biotinylated probes-Mix I: $(\text { AAGC })_{5}$, $(\mathrm{AACC})_{5},(\mathrm{AACG})_{5},(\mathrm{ATCC})_{5},(\mathrm{AAGG})_{5}$; Mix II: $(\mathrm{ATC})_{8}$, $\mathrm{G}(\mathrm{AGG})_{6}, \mathrm{G}(\mathrm{CCG})_{5},(\mathrm{AAT})_{10},(\mathrm{AAG})_{8},(\mathrm{ACT})_{8},(\mathrm{AAC})_{8}$, 
Table 1 Locus name, repeat motif, primer sequences, annealing temperature $\left(T_{\mathrm{a}}\right)$ and approximate size of expected product for one nuclear coding region and eight microsatellites for $M$. capitata and seven microsatellites from A. cytherea

\begin{tabular}{|c|c|c|c|c|c|}
\hline Taxa & Locus & Motif & Primer sequence $\left(5^{\prime}-3^{\prime}\right)$ & $T_{\mathrm{a}}\left({ }^{\circ} \mathrm{C}\right)$ & Size $(b p)$ \\
\hline \multirow[t]{18}{*}{ M. capitata } & \multirow[t]{2}{*}{ atpsb } & & F: TGA TTG TGT CTG GTG TAA TCA GC & \multirow[t]{2}{*}{53} & \multirow[t]{2}{*}{$200-201$} \\
\hline & & & R: CGG GCA CGG GCG CCG GGG GGT TCG TTC AT & & \\
\hline & \multirow[t]{2}{*}{ Mc0004 } & \multirow[t]{2}{*}{$(\mathrm{AATC})_{9}$} & F: T3-TGA AAT AAG CAG GAT CCA TGT G & \multirow[t]{2}{*}{55} & \multirow[t]{2}{*}{$389-414$} \\
\hline & & & R: AGG TAA ATG CCA GAA TTG GAA A & & \\
\hline & \multirow[t]{2}{*}{ Mc0067 } & \multirow[t]{2}{*}{$(\mathrm{TGAG})_{13}$} & F: T1-AAG AAC ACC AAA CAA CCG AAC T & \multirow[t]{2}{*}{55} & \multirow[t]{2}{*}{$215-255$} \\
\hline & & & R: GGT TAG CGC TCT TGT GCT AAA T & & \\
\hline & \multirow[t]{2}{*}{ Mc0163 } & \multirow[t]{2}{*}{$(\mathrm{TCAC})_{12}$} & F: T4—TTA TTT CTC GTG TAT CGC CCT T & \multirow[t]{2}{*}{55} & \multirow[t]{2}{*}{ 239-309 } \\
\hline & & & R: AGA CAG AGC GGT TGG TGT AAA T & & \\
\hline & \multirow[t]{2}{*}{$\mathrm{Mc0701}$} & \multirow[t]{2}{*}{$(\mathrm{TTCC})_{10}$} & F: T2-CAG TGC GAG AAC GAC TAG AGA C & \multirow[t]{2}{*}{55} & \multirow[t]{2}{*}{$223-251$} \\
\hline & & & R: AAA ATG ACA AGC ATG TTG GTG T & & \\
\hline & \multirow[t]{2}{*}{ Mc0797 } & \multirow[t]{2}{*}{$(\mathrm{CCT})_{6}$} & F: T3-CTT TCA AGG TGT TGA TGC CAT A & \multirow[t]{2}{*}{55} & \multirow[t]{2}{*}{$302-308$} \\
\hline & & & R: GGC ACA TCA TGA GAA CAT CAG T & & \\
\hline & \multirow[t]{2}{*}{$\mathrm{Mc0872}$} & \multirow[t]{2}{*}{$(\mathrm{AAC})_{7}$} & F: T4_TGG CCA GCT TAG TGT TAG TTG A & \multirow[t]{2}{*}{55} & \multirow[t]{2}{*}{$388-402$} \\
\hline & & & R: GTT CTT GTA TTT GAC TTG CCC C & & \\
\hline & \multirow[t]{2}{*}{ Mc0903 } & \multirow[t]{2}{*}{$(\mathrm{ATG})_{9}$} & F: T1—CAT CTA GAA TTA GCG GGA TGC T & 55 & $281-297$ \\
\hline & & & R: CAG AAG TTC CGA CTT TCG ACT T & & \\
\hline & Мc0947 & $(\mathrm{ATG})_{7}$ & F: T2_-TAG GGG TAA GGA AGG TTG AAC A & 55 & $304-336$ \\
\hline & & & R: AAG GGA AAC GGT AAG ACA TGA A & & \\
\hline A. cytherea & Ac0753 & $(\mathrm{CAT})_{7}$ & F: T2—GCG AAA GAG ATT CCG TTA GAG A & 55 & 294-306 \\
\hline & & & R: AAT GGG CTC AAT TTC CCT TAA T & & \\
\hline & Ac0808 & $(\mathrm{TGA})_{6}$ & F: T3-TTT TAG CTG GAG ATG ACG ATG A & 55 & 184-190 \\
\hline & & & R: TAA CAG GAA AAG GGA AAC AAG G & & \\
\hline & Amil2_002 ${ }^{\dagger}$ & $(\mathrm{TG})_{10}$ & F: T1—ACA AAA TAA CCC CTТ CTA CCT & 55 & $140-153$ \\
\hline & & & R: CTT CAT CTC TAC AGC CGA TT & & \\
\hline & Amil2_ $006^{\dagger}$ & $(\mathrm{CA})_{4} \mathrm{TA}(\mathrm{CA})_{4}$ & F: T2-CTT GAC CTA AAA AAC TGT CGT ACA A & 55 & $115-119$ \\
\hline & & & R: GTT ATT ACT AAA AAG GAC GAG AAT AAC TTT & & \\
\hline & Amil2_ $007^{\dagger}$ & $(\mathrm{TG})_{7} \mathrm{AG}$ & F: T4_TAA TGA GCA AAC TCA TTC ATG G & 55 & $116-121$ \\
\hline & & & R: CTT TTC CAA GAG AAG TCA AGA A & & \\
\hline & Amil2_022 ${ }^{\dagger}$ & $(\mathrm{AC})_{10}$ & F: T4—CTG TGG CCT TGT TAG ATA GC & 55 & $109-131$ \\
\hline & & & R: AGA TTT GTG TTG TCC TGC TT & & \\
\hline & Amil2_023 ${ }^{\dagger}$ & $(\mathrm{AG})_{7}$ & F: T3-GCA AGT GTT ACT GCA TCA AA & 55 & $148-150$ \\
\hline & & & R: TCA TGA TGC TTT ACA GGT GA & & \\
\hline
\end{tabular}

T1: PET-5'-GGCTAGGAAAGGTTAGTGGC-3'; T2: 6-Fam-5'-TCATACATGTCTCTCAGCGTAAAC-3'; T3: NED-5'-ACCAACCTAGG AAACACAG-3'; T4: VIC-5'-GACTATGGGCGTGAGTGCAT-3'

$(\mathrm{ACG})_{6},(\mathrm{ACC})_{6},(\mathrm{AGC})_{6}$ (Toonen 1997). Fragments with sequences complementary to these probes were captured with Streptavidin M-280 Dynabeads (Invitrogen, Carlsbad, CA, USA). DNA enriched for these tri- and tetranucleotide microsatellite repeat motifs was ligated into T-tailed pZErO-2 plasmids using a Topo-TA cloning kit (Invitrogen). Escherichia coli $\alpha$-select chemically competent cells (Bioline Inc., Springfield, NJ, USA) were transformed with the recombinant plasmids. Across all four species, 8,064 clones were picked using a VersArray Colony Picker (Biorad) and subsequently consolidated into and re-grown in 384 well sample plates. Colonies from the 384 well plates were then imprinted and grown directly on nitrocellulose membranes resting on LB agar plates and incubated overnight at $37^{\circ} \mathrm{C}$. Following Toonen (1997), DNA was extracted and fixed on the membrane and was subsequently screened for microsatellite positive colonies by hybridization with the same biotinylated oligonucleotide probe mixtures as above with a modified colorimetric detection step using chemiluminescent CDP-star (\#N7001S NEB Biolabs) and subsequent exposure to Kodak ${ }^{\circledR}$ X-Ray film. 1,423 colonies were identified as containing microsatellite repeats. 1,039 clones from A. cytherea, $F$. scutaria and $M$. capitata were amplified and submitted for sequencing at the Hawai' $i$ Institute of Marine Biology EPSCoR Facility, while 384 clones from P. lobata were amplified and 


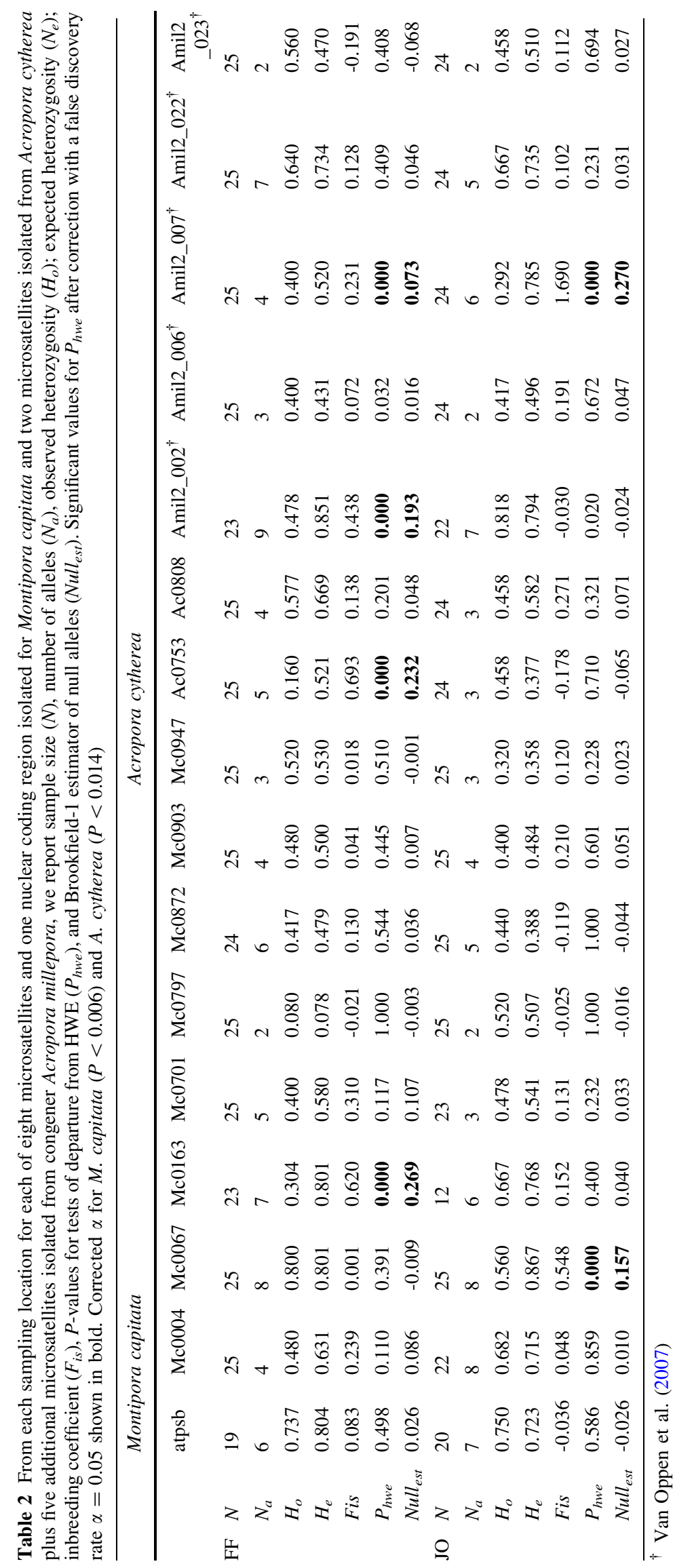


sequenced at the Huck Institute for the Life Sciences, Pennsylvania State University. The STADEN-Troll pipeline (Martins et al. 2006) was used to identify tandem repeats. Primers were designed using PRIMER 3 for each of 50, 118, 140, and 149 sequences from A. cytherea, F. scutaria, $M$. capitata and $P$. lobata, respectively. Primer sequences as well as the genus, species, bitscore and e-value for the top BLASTn hit (Altschul et al. 1990) can be found in Supplemental Table 1.

Due to time constraints and cost, primers were ordered and tested for only the first 50 putative loci from M. capitata and $A$. cytherea. Primers were screened with a low annealing temperature $\left(48^{\circ} \mathrm{C}\right) \mathrm{PCR}$ against DNA extracts from pure zooxanthellae cultures provided by RA Kinzie believed to represent clades A, B and C isolated from Cassiopea sp. (KB8), Aiptasia pulchella (HIAp) and Montipora verrucosa $(\mathrm{Mv})$, respectively. They were subsequently screened against host genomic DNA with an annealing temperature of $55^{\circ} \mathrm{C}$. We used the tailed three primer method described by Gaither et al. (2009). Tails were added to the $5^{\prime}$ end of all forward primers that successfully amplified host genomic DNA, but not symbiont DNA (Table 1). PCRs were as follows: each $10 \mu \mathrm{l}$ reaction contained: $1 \mu \mathrm{l} 10 \times \mathrm{NH}_{4}$ reaction buffer, $0.6 \mu \mathrm{l} 50 \mathrm{mM} \mathrm{MgCl} 2,0.4 \mu \mathrm{l} 10 \mathrm{mM}$ total dNTPs ( $2.5 \mathrm{mM}$ each), $0.35 \mathrm{pmol}$ tailed forward primer, $1.5 \mathrm{pmol}$ reverse primer, 1.5 pmol oligonucleotide dye label, 2-25 ng of template DNA, $0.1 \mu \mathrm{l}$ of Biolase polymerase (Bioline Inc.), and deionized water to volume. PCR amplification was performed on a BioRad MyCycler ${ }^{\mathrm{TM}}$ as follows: $95^{\circ} \mathrm{C}$ for $10 \mathrm{~min}(1 \mathrm{cycle}), 94^{\circ} \mathrm{C}$ for $30 \mathrm{~s}, 55^{\circ} \mathrm{C}$ for $30 \mathrm{~s}, 72^{\circ} \mathrm{C}$ for $30 \mathrm{~s}$ ( 35 cycles), followed by a final extension of $72^{\circ} \mathrm{C}$ for 30 min (1 cycle).

Eight primer pairs for Montipora capitata, and two primer pairs for Acropora cytherea in addition to five primer pairs from van Oppen et al. (2007) successfully amplified polymorphic loci and were selected for further genotyping of samples (Table 1). Fragments were analyzed on an ABI 3130XL Genetic Analyzer at the Hawai' $i$ Institute of Marine Biology and sized using GENEMAPPER v4.0 and GS500LZ size standards (Applied Biosystems, Inc.). ArLeQuin 3.11 (Excoffier et al. 2005) was used to calculate genotypic disequilibrium, heterozygosity, and probability of departure from HWE. Each primer pair was initially screened for variability against 25 individuals sampled from each of French Frigate Shoals and Johnston Atoll (Table 2). The number of alleles for each locus ranged from 2 to 9 for both species (Table 2). No linkage was detected in either population for A. cytherea, and M. capitata. After controlling for false discovery rate (Benjamini and Yekutieli 2001), significant departures from HWE were detected in six out of 32 comparisons (Table 2). MicroCheCKER (van Oosterhout et al. 2004) detected no evidence of scoring errors, or large-allele dropout in either species, although possible null alleles were likely at each locus that showed significant departure from HWE in a population (Table 2).

Additionally, forward and reverse primers for ATP synthethase $\beta(\operatorname{atps} \beta)$ (Jarman et al. 2002) were redesigned for specificity in the genus Montipora with PCR conditions following Concepcion et al. (2008). This locus was also sequenced directly for each individual from each population $(n=50)$. Computational methods for determining phase of diploid sequence data is more cost effective and can be as accurate as cloning (Harrigan et al. 2008). Therefore, we used PHASE (Stephens et al. 2001; Stephens and Donnelly 2003) as implemented in DNASP (Librado and Rozas 2009) for determining gametic phases (Table 2).

The use of microsatellites to study coral population genetics is still in its infancy. We hope this library of both characterized, and untested microsatellite loci will provide a wealth of population genetic tools to aid studies both inside and outside of Hawai ' $i$, in species of corals other than the four for which they were isolated, as well as providing possible microsatellite markers for the symbionts (Symbiodinium spp.)

Acknowledgments We'd like to thank R. Brainard, M. Crepeau, E. Franklin, S. Godwin, M. Iacchei, J. Maragos, J. Salerno, D. Skillings, M. Stat, M. Timers, the staff of the Papahānaumokuākea Marine National Monument, and the crew of the R/V Hi'ialakai for sample collection, field and laboratory assistance. We also thank members of the Toonen-Bowen laboratory for their discussion, advice and support, and the NSF-EPSCoR Evolutionary Genetics facility at HIMB. This research was funded in part by the National Science Foundation (Grant OCE-0550294 to IBB, OCE- 0623678 to RJT, an NSF pre-doctoral fellowship to NRP, and an NSF EPSCoR pre-doctoral fellowship to GTC) and the National Oceanic and Atmospheric Administration (NMSP MOA\#2005-008/66882). This is contribution 1366 from the Hawai'i Institute of Marine Biology and SOEST 7818.

Open Access This article is distributed under the terms of the Creative Commons Attribution Noncommercial License which permits any noncommercial use, distribution, and reproduction in any medium, provided the original author(s) and source are credited.

\section{References}

Altschul SF, Gish W, Miller W, Myers EW, Lipman DJ (1990) Basic local alignment search tool. J Mol Biol 215(3):403-410

Benjamini Y, Yekutieli D (2001) The control of the false discovery rate in multiple testing under dependency. Ann Stat 29:11651188

Concepcion GT, Medina M, Toonen RJ (2006) Noncoding mitochondrial loci for corals. Mol Ecol Notes 6:1208-1211

Concepcion GT, Crepeau MW, Wagner D, Kahng SE, Toonen RJ (2008) An alternative to ITS a hypervariable single-copy nuclear intron in corals and its use in detecting cryptic species within the octocoral genus Carijoa. Coral Reefs 27:323-336

Excoffier L, Laval G, Schneider S (2005) Arlequin (version 3.0): an integrated software package for population genetics data analysis. Evol Bioinform Online 1:47-50 
Gaither MA, Toonen RJ, Sorenson L, Bowen BW (2009) Isolation and characterization of microsatellite markers for the Crimson Jobfish, Pristipomoides filamentosus (Lutjanidae). Conservation Genet Resour. doi:10.1007/s12686-009-9119-3

Glenn BT, Schable NA (2005) Isolating microsatellite DNA loci. Methods Enzymol 395:202-222

Harrigan RJ, Mazza ME, Sorenson MD (2008) Computation vs. cloning: evaluation of two methods for haplotype determination. Mol Ecol Resour 8:1239-1248

Jarman SN, Ward RD, Elliott NG (2002) Oligonucleotide primers for PCR amplification of coelomate introns. Mar Biotechnol 4: 347-355

Levin LA (2006) Recent progress in understanding larval dispersal: new directions and digressions. Integr Comp Biol 46:282-297

Librado P, Rozas J (2009) DnaSP v5: a software for comprehensive analysis of DNA polymorphism data. Bioinformatics 25:14511452. doi:10.1093/bioinformatics/btp187

Martins W, de Sousa D, Proite K, Guimarães P, Moretzsohn M, Bertioli D (2006) New software for automated microsatellite marker development. Nucleic Acids Res 34:e31

Rozen S, Skaletsky H (1999) Primer3 on the WWW for general users and for biologist programmers. In: Krawetz S, Misener S (eds)
Bioinformatics methods and protocols: methods in molecular biology. Humana Press, Totowa, pp 365-386

Selkoe KA, Toonen RJ (2006) Microsatellites for ecologists: a practical guide to using and evaluating microsatellite markers. Ecol Lett 9:615-629

Stephens M, Donnelly P (2003) A comparison of bayesian methods for haplotype reconstruction from population genotype data. Am J Hum Genet 73:1162-1169

Stephens M, Smith NJ, Donnelly P (2001) A new statistical method for haplotype reconstruction from population data. Am J Hum Genet 68:978-989

Toonen RJ (1997) Microsatellites for ecologists: non-radioactive isolation and amplification protocols for microsatellite markers. http://www2.hawaii.edu/ toonen/files/Msats-for-Ecologists-V1. pdf

van Oosterhout C, Hutchinson WF, Wills DP, Shipley P (2004) Micro-checker: software for identifying and correcting genotyping errors in microsatellite data. Mol Ecol Notes 4:535-538

van Oppen MJ, Underwood JN, Muirhead AN, Peplow L (2007) Ten microsatellite loci for the reef-building coral Acropora millepora (Cnidaria, Scleractinia) from the Great Barrier Reef, Australia. Mol Ecol Notes 7:436-438 